\title{
Intracranial Atherosclerosis: Where Are We Now?
}

\author{
Jong S. Kim \\ Editor-in-Chief, Journal of Stroke
}

Intracranial atherosclerosis (ICAS) is an important cause of stroke in Asians, Africans, and Hispanics. 'Because these ethnic groups account for more than $70 \%$ of the world's population, ICAS can be considered a major cause of ischemic stroke worldwide. Nevertheless, as compared to extracranial atherosclerosis, ICAS has been largely neglected in the literature. Now, partly due to the development of imaging and therapeutic technologies, and partly because of active research in various parts of the world, the importance of ICAS is being more properly appreciated.

This issue of the Journal of Stroke (JoS) published three review papers on ICAS. Subjects included ICAS pathology in the era of high resolution $\mathrm{MRI}_{1}{ }^{2}$ an update on medical management, ${ }^{3}$ and the current status of angioplasty/stenting. ${ }^{4} \mathrm{Al}-$ though the reviews updated available knowledge on ICAS, I feel that there is still ambiguity in the diagnostic and treatment strategies. Recent clinical and high-resolution MRI studies have shown that not all ICAS is the same: some cases are symptomatic, while others are silent, and some present as artery-to-artery embolisms, while others develop branch occlusion. Moreover, high-resolution MRI findings are often inconsistent with atherosclerosis, especially in young subjects who are diagnosed with ICAS; the features instead favor nonatherosclerotic vasculopathy such as dissection, vasculitis, and moyamoya disease. ${ }^{5}$ Thus, we have to be cautious in interpreting the data from previous studies in which the samples might have been inhomogeneous.

The magnitude of heterogeneity in study samples may differ according to ethnicities. Intracranial dissection, vasculitis, and moyamoya disease appear to be more common in Asians than in Caucasians; this is partly attributed to differences in genetic predisposition. For example, RING finger protein (RNF) gene polymorphism, which confers susceptibility to moyamoya disease and possibly ICAS, is more prevalent in Asians than in other ethnicities. ${ }^{6}$ In the future, we may have to place more emphasis on proper diagnosis and characterization of stenotic intracranial arteries, and trials of antithrombotics, statins, or angioplasty/stenting may have to be based on more homogeneous populations. Hopefully, these efforts will give us answers for yet unclear issues such as: why are there East-West differences in the location of atherosclerosis; what is the best antithrombotic; what is the adequate intensity of statin dosing; and who are the patients who may benefit from angioplastyl stenting or bypass surgery? Although three reviews cannot provide the correct answers, they will stimulate the readership and serve as a useful guide in future research.

Finally, I am delighted to inform you that the impact factor of JoS has increased from 4.795 in the last year to 5.576. I sincerely thank all the editorial team members for their hard work, contributors who submitted excellent research articles, and those who willingly cited the JoS papers in their works. I am indebted to all of them.

\section{References}

1. Bang OY. Intracranial atherosclerosis: current understanding and perspectives. J Stroke 2014;16:27-35.

2. Yang WJ, Wong KS, Chen XY. Intracranial atherosclerosis: from microscopy to high-resolution magnetic resonance imaging. J Stroke 2017;19:249-260.

3. Kim JS, Bang OY. Medical treatment of intracranial atherosclerosis: an update. J Stroke 2017;19:261-270.

4. Wabnitz A, Chimowitz M. Angioplasty, stenting and other potential treatments of atherosclerotic stenosis of the intracranial arteries: past, present and future. J Stroke 2017;19:271276.

5. Ahn SH, Lee J, Kim YJ, Kwon SU, Lee D, Jung SC, et al. Isolated MCA disease in patients without significant atheroscle- 
rotic risk factors: a high-resolution magnetic resonance imaging study. Stroke 2015;46:697-703.

6. Fujimura $M$, Sonobe $S$, Nishijima $Y$, Niizuma $K$, Sakata $H$, Kure $S$, et al. Genetics and biomarkers of moyamoya disease: significance of RNF213 as a susceptibility gene. J Stroke 2014;16:65-72.
Correspondence: Jong S. Kim

Department of Neurology, Asan Medical Center, University of Ulsan College of Medicine, 88 Olympic-ro 43-gil, Songpa-gu, Seoul 05505, Korea

Tel: +82-2-3010-3442

Fax: +82-2-474-4691

E-mail: jongskim@amc.seoul.kr

The authors have no financial conflicts of interest. 